\title{
El artista plástico Hélio Oiticica: escritor y fotógrafo
}

Mario Cámara

CONICET/ Universidad de Buenos Aires - Argentina

\begin{abstract}
Resumo
O artigo explora a dimensão literária e fotográfica do artista visual Hélio Oiticica. Para isso enxerga na série de Bólides que Oiticica dedicou aos bandidos Cara Cavalo e Alcir Figueira, o B33 Bólide-caixa 18 "Homenagem a Cara de Cavalo" - caixa-poema, o B44 Bólide-caixa 21 caixa-poema 3: porque impossibilidade? e o B56 Bólidecaixa 24 "Caracara Cara de Cavalo, e o estandarte-bandeira Seja marginal, seja herói, que reproduz a imagem do Bólide B44. O objetivo do texto é analisar os processos de apropriação postos em jogo por Oiticica, sobre tudo porque ele trabalha com fotografias públicas e privadas dos bandidos. A leitura é completada ligando tais fotografias com textos-poemas e textos-slogans produzidos para esses Bólides e para o estandarte-bandeira.
\end{abstract}

Palavras chave: fotografia; escrita; apropriação; marcos.

\section{Resumen}

El artículo indaga en la dimensión literaria y fotográfica del artista visual Hélio Oititica. Para ello se concentra en la serie de Bólides que Oiticica dedicó a los bandidos Cara de Cavalo y Alcir Figueira, el B33 Bólide-caixa 18 "Homenagem a Cara de Cavalo"- caixa-poema, el B44 Bólide-caixa 21 caixa-poema 3: porque a impossibilidade? y el B56 Bólidecaixa 24 "Caracara Cara de Cavalo, y al estandarte-bandera Seja marginal, seja herói, que reproduce la imagen del Bólide B44. El objetivo del texto consiste en analizar los procesos de apropiación y reenmarque que allí pone en juego Oiticica teniendo en cuenta que trabaja con fotografías públicas y privadas de los bandidos. La lectura se completa poniendo en relación tales fotografías con los textos-poemas y textos-eslogans producidos para los Bólides y para el estandarte-bandera.

Palabras clave: fotografía; escritura; apropiación; marcos. 
1. Sobre el proyecto de libro de Hélio Oiticica remito al ensayo de COELHO, Fred. Livro on

Livro-me. Os escritos babilónicos de Hélio Oiticica (1971-1978), 2008.
Hélio Oiticica siempre quiso ser escritor y, de muchas maneras, lo fue. Durante su estancia en New York, entre 1971 y 1978, planeó un libro al que bautizó originalmente como Neworkaises y luego Conglomerado. ${ }^{1}$ A pesar de que ese proyecto no fue culminado y de que no publicó ningún texto de ficción en vida, su archivo permite comprobar que su producción textual fue, aún antes de New York, prolífica e intensa. Entre sus archivos, por ejemplo, encontramos diarios, poemas y cuentos. Desde muy temprano, Oiticica introdujo textos en su obra plástica. Durante los años sesenta, en sus Bólides y en sus Parangolés estampó poemas y consignas, muchos de los cuales tuvieron una amplia difusión, como por ejemplo el famoso " $\mathrm{Da}$ adversidade vivemos" pintado en el Parangolé P 16, Capa 12, de 1964, o "Pureza é um mito" grabado en su instalación Tropicalia (1967). Frente a tales inscripciones, que en muchos casos remiten al arte de la consigna callejera o el eslogan publicitario, quizá sea necesario preguntarse qué tipo de relación establecieron con el objeto plástico, con el Parangolé, con el Bólide o con la instalación, de qué modo se entrecruzaron, se transformaron, se potenciaron.

Hay una serie de obras de Oiticica que me parecen relevantes para pensar en esos cruces, y para redimensionar la importancia de sus textos, muchas veces leídos como mero comentario de la imagen. Esas obras son los Bólides dedicados a bandidos brasileños, realizados entre 1965 y 1967, y el estandarte-bandera realizado en 1968, donde estampa otra de sus famosas consignas, quizá la más famosa, "Seja marginal, seja héroi”. En estos Bólides, y en el estandarte-bandera, además de utilizar poemas y consignas, Oiticica se apropia de un conjunto de fotografías de los bandidos, registro poco frecuente en su obra. El cruce entre palabras, cuerpos y rostros resultan centrales para describir una serie de tensiones que atravesaron su proyecto artístico, centradas en los modos de exhibición y de apelación a un público espectador o participante.

\section{Lo imborrable}

El 5 de octubre de 1964 muere asesinado por la policía brasileña el bandido Cara de Cavalo. Su muerte fue consecuencia de un enfrentamiento anterior en el que el bandido, perseguido, había matado a un policía. Las noticias de la prensa siguieron atentamente la persecución y muchas de ellas hablaron de "cacería". Como ha señalado Gonzalo Aguilar, a partir de la muerte del policía comenzó la caza de Cara de Cavalo: 
La palabra caza así como venganza son las más reiteradas en los periódicos de la época. Con ambas palabras, los policías establecían una frontera imaginaria absoluta entre ellos y el bandido, que no parecía tan marcada cuando ambos - malandros y policías- disfrutaban las bondades del jogo de bicho clandestino. Con la figura de la caza, los policías, la prensa y la "opinión pública" (esa entelequia) hacen de Cara de Cavalo un animal y de la persecución un juego serio que sólo terminará con su muerte (y con su cuerpo como trofeo). Así, Manuel descubre otro de los sentidos de su sobrenombre: Cara de Cavalo. Donde se inscribe lo humano (el rostro, la "cara"), la persecución remarca lo animal, ese umbral en el que el otro (el bárbaro, el bandido, el delincuente) se transforma en bestia. Humano y animal no se distinguen en una persona a la que los periódicos nunca mencionan por su nombre civil. Manuel Moreira pierde su nombre y su civilidad para ser arrojado a la zona del sacrificio. ${ }^{2}$

Hélio Oiticica dedicó dos de sus Bólides a Cara de Cavalo. El primero lo produjo en 1966 y lo tituló Homenagem a Cara de Cavalo, el segundo lo presentó en 1968 bajo el nombre de Caracara de Cara de Cavalo. Entre uno y otro, construyó su Bólide homenaje a Alcir Figueira, que se había suicidado al verse acorralado por la policía después de robar un banco. De este Bólide surgirá en 1968 la bandera-estandarte con la consigna "Seja marginal, seja herói”.

Los Bólides habían surgido como superación de la etapa de los Penetrables y Oiticica los desarrolló conjuntamente con su proyecto Parangolés, capas portables con las que los espectadores-participantes debían danzar. Los primeros treinta que produjo hasta 1965 utilizaron recipientes de vidrio rellenos con materiales diversos como carbón, piedras, pigmentos, porotos negros y fragmentos de vidrio. Luego, los recipientes fueron más variados, incluyendo cubetas de metal, carretillas, cajas de madera, latas de pintura y cestos de basura. El Bólide buscaba dar al color una nueva y más corpórea estructura, y formaba parte del proyecto, compartido con muchos otros artistas brasileños, de romper el marco del cuadro y promover la participación del espectador. Al recipiente que contenía los colores en forma de materia, Oiticica los denominó objetos premoldeados, puesto que eran recipientes existentes y de circulación masiva que podían ser comprados en bazares o ferreterías.

O que faço ao transformá-lo numa obra não é a simples "lirificação" do objeto, ou situá-lo fora do cotidiano, mas incorporá-lo a uma idéia, fazê-lo parte da gênese da obra, tomando ele assim um caráter transcendental, visto participar de uma idéia universal sem perder a sua estrutura anterior. Daí a designação de "transobjeto" adequada à experiência."
2. "La ley del bandido, la ley del arte. Bólide caixa 18 poema Caixa 2, Homenagem a Cara de Cavalo de Hélio Oiticica", 2009, p. 541. Aguilar plantea una lectura que parte de la trayectoria vital de Cara de Cavalo, es decir, de la muerte por enfrentamiento con Le Cocq, y luego la persecución policial hasta la muerte final.

\section{Apud VARELA LOEB,} Angela, "Os bólides do Programa Ambiental de Hélio Oititica", 2011, p. 52. 
4. En una entrevista, cuando le preguntaron por las apropiaciones respondió lo siguiente: 'Las 'apropiaciones' son cosas o conjuntos de cosas del mundo de las que me apropio y que declaro obras; y esto sucede por la identificación entre lo que llamo el 'sentido estructural' del artista (cada uno tiene el suyo) y de la cosa apropiada", Cf. OITICICA, Hélio. Materialismos. Buenos Aires: Manantial, 2013. Por otra parte, en su Programa Ambiental (1966), Oiticica conceptualiza lo que quiere decir con "apropiaciones" y utiliza dicha palabra en cuatro piezas: B36 Bólide-caixa 19 APROPRIACAOO 1; B38 Bólide-lata 1 APROPRIACÃO 2 "consumitive"; $B 39$ Bólideluг 1 APROPRIACÃO 3 "plasticope" e B49 Bólide-saco 1 APROPRIAC ÁO 499.

\section{Apud VARELA LOEB,}

Angela, "Os bólides do Programa Ambiental de Hélio Oititica”, 2011., p. 72.

6. Oiticica no volvió a utilizar fotografías hasta su proyecto Coscomocas, que en verdad nunca fue montado en vida del artista. Concretado muchos años después, se observa la utilización de imágenes de músicos de rock provenientes de tapas de discos, como por ejemplo de Yoko Ono y Jimi Hendrix. Otra excepción podría ser el parangolé dedicado a Che Guevara, para el que Oiticica utilizó la famosa fotografía de Antonio Korda, aunque bajo la forma esténcil.
De un modo semejante al ready made de Marcel Duchamp, el Bólide era una forma de apropiación ${ }^{4}$ en la que el objeto serializado con una función social específica, comenzaba a ser utilizado de otro modo por los espectadores participantes. Un primer uso era lúdico, pues el espectador interactuaba sensorialmente con los materiales contenidos. Pero a diferencia del ready made, que suspende y neutraliza un objeto cotidiano, el Bólide lo utilizaba para liberar otras potencialidades sin desactivar por completo su funcionalidad originaria, lo que en teoría le permitía al objeto irradiar al objeto nuevos sentidos hacia el afuera. Como si una cubeta convertida en Bólide, más que suspender su valor de uso, difuminara nuevos usos hacia la serie de "cubetas" que habían permanecido en el mundo profano. Sobre el Bólide B 38, que consiste en una lata ardiendo con fuego en su interior, de esas que hasta hace algunos años se utilizaban para señalizar una obra o refacción realizada en la vía pública, Oiticica afirmaba: "Quem viu a lata-fogo isolada como uma obra não poderá deixar de lembrar que é uma 'obra' ao ver, na calada da noite, as outras espalhadas como que sinais cósmicos, simbólicos, pela cidade" ${ }^{5}$ La declaración del artista revela uno de los vectores, no el único, de su proyecto artístico, la confianza en que su arte era capaz de estetizar la vida cotidiana.

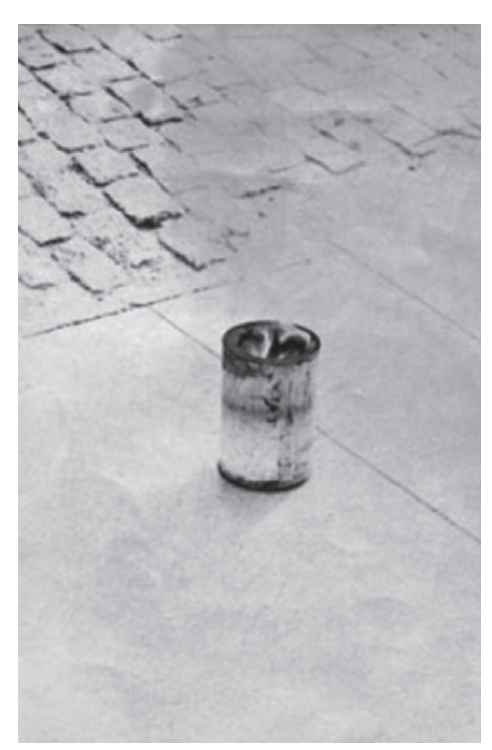

Fig. 1. BOLIDE B38

Los Bólides dedicados Cara de Cavalo y a Alcir Figueira, tres en total, supusieron una excepción en términos formales no solo porque utilizaron fotografías, sino porque Oiticica buscó producir un efecto de suspensión del juicio, más volcado a la contemplación que a la participación del espectador. ${ }^{6} \mathrm{El}$ procedimiento retrabajó la figura del bandido sustrayéndolo tanto de la condena como de la fácil identificación, haciéndolos ingresar en un régimen de indeterminación que exponía una 
presencia histórica y situada $y$, al mismo tiempo, singular, intransferible y colectiva. La bandera estandarte, en cambio, se orientó, en línea con los Parangolés, a producir la participación del espectador en el espacio público. La relación de su arte con los bandidos se puede pensar, de este modo, como compuesta por movimientos de retracción y de expansión que escenifican modos conflictivos de pensar el arte en los sesenta, tensionado por una solicitud de quietud y contemplación, algo así como un sitio de resistencia frente a la reificación cotidiana, y por otra parte dispuesto a derramarse sobre lo social, estetizándolo y transformándolo.

Para la construcción del primer Bólide, en mayo de 19667, el B33 Bólide-caixa 18 "Homenagem a Cara de Cavalo"-caixa-poema, Oititica utilizó la fotografía de Cara de Cavalo que había aparecido en la edición del 4 de octubre de 1964 del diario Jornal do Brasil, ilustrada con el siguiente título: "Cara de Cavalo assassinado com 52 tiros em Cabo Frio". ${ }^{8}$ El mismo procedimiento utilizó en su segundo Bólide, construido entre 1966 y 1967, el B44 Bólide-caixa 21 caixa-poema 3: porque a impossibilidade?, dedicado al bandido Alcir Figueira, que se convertirá, como anticipé, en el estandarte-bandera "Seja marginal, seja héroi". Y para el último Bólide, de 1968, que volvió a dedicar a Cara de Cavalo, el B56 Bólidecaixa 24 "Caracara Cara de Cavalo", Oiticica se valió de una fotografía perteneciente al documento de identidad del bandido.?

En relación al primer Bólide, la fotografía del periódico mostraba el cadáver del bandido inerte sobre el suelo, luego de ser acribillado por la policía. Se trataba de una clásica fotografía de prensa que intenta documentar un hecho policial. Más que ícono, lo que allí aparecía era un corpus delicti, o sea una prueba del accionar policial en contra de un bandido al que los propios medios habían construido como altamente peligroso. Enmarcada de ese modo en el periódico, esa fotografía era pura indicialidad. El Bólide construido por Oiticica consistió en un rectángulo de madera negra, con uno de sus lados en posición horizontal y la reutilización de la fotografía de tapa del diario ampliada, pero sin título ni pie de página, pegada en las cuatro caras interiores del rectángulo, de manera que semejara un reflejo de un lado sobre otro de la caja. En la base del Bólide, Oiticica había dispuesto una bolsa plástica rellena con cadmio de coloración rojiza y sobre el plástico el siguiente texto-poema: “Aquí está, / e ficará! / Contemplai / o seu / silêncio / heroico". ${ }^{10}$ El Bólide se completaba con una tela de nylon manchada y extendida perpendicularmente sobre la caja.
7. Los primeros bocetos del Bólide son de junio de 1965. Allí, la decisión de trabajar con la fotografía de tapa del Jornal do Brasil de octubre de 1964 ya está tomada.

8. En el documento nº 249 del archivo Hélio Oiticica figura el recibo de compra al Jornal do Brasil de ocho fotografías al Jornal do Brasil el 19 de abril de 1966 por 32000 cruzeiros.

9. Oiticica expuso el B33 Bólidecaixa 18 "Homenagem a Cara de Cavalo"- caixa-poema y el B44 Bólide-caixa 21 caixa-poema 3: porque a impossibilidade?, en la exposición colectiva organizada por Frederico Morais titulada "O artista Brasileiro e a Iconografia de Massa”, realizada en 1968.

10. En el documento n 357 encontramos otro poema dedicado a Cara de Cavalo: "qual a nova cara / de cavalo / asscalho / ou o baralho da vida / pútrido odor / sabor / salabor / salibidor / da tua tumba não o horror / nem dor / apenas um tremor / o imponderável / o terceiro / ou o quarto mundo / quarto imundo / mas palpável / ele é e existe / não é triste / é triste / como a artrite que nos acomete / no pântano / ou no apartamento / de cimento / o cimento que cobre o ato / o tato / o crime / que já deixa de ser". La datación del poema es del 3 de noviembre de 1968, pocos días antes de que Oiticica partiera para Londres. 


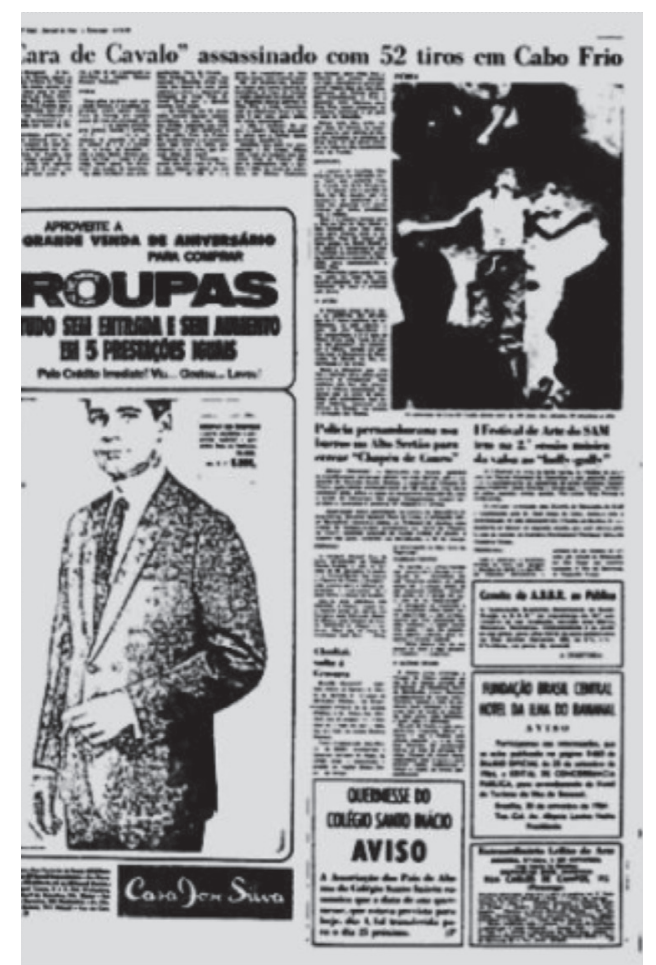

Fig. 2. Fotografía de Cara de Cavalo en la prensa

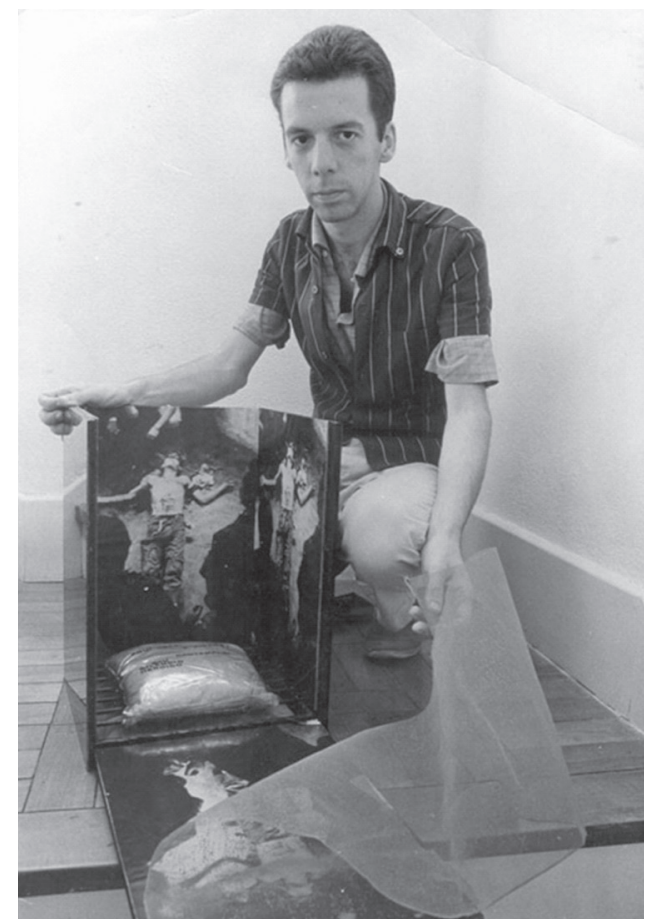

Fig. 3. Bólide B 33 caixa-18

La elección de esa (y no otra) fotografía de Cara de Cavalo no parece casual. La prensa escrita había cubierto intensamente la persecución del bandido y había una importante disponibilidad de imágenes. En plena dictadura militar, lo que le atrajo a Oiticica de esa imagen en particular fue la pose del cuerpo con 
los brazos abiertos, que remitía de inmediato a ciertas escenas de la crucifixión de Cristo representadas por la pintura italiana entre los siglos XIV y XVI. ${ }^{11}$ El Cristo bajado de la cruz encarna el momento de mayor fragilidad del calvario, cuando su cuerpo se encuentra efectivamente muerto y sus fieles desconocen su pronta resurrección.

La pose crística de Cara de Cavalo transformaba la caja que la contenía en una suerte de urna mortuoria, y el conjunto era subrayado por la utilización del pigmento rojo y la tela nylon que funcionaba como un velo manchado con sangre. De este modo, arrojado frente a nuestros ojos, estático, lo que parece emerger es la construcción de un mártir. ${ }^{12}$ De alguna manera, en el pasaje del dominio de la prensa al dominio del arte, Oiticica convertía el corpus delicti en pose y cita crística. Sin embargo, suscribir ese único sentido para este Bólide se vuelve conflictivo cuando vamos de la imagen al poema o del poema a la imagen. Este recorrido o interfaz produce un reenmarque de la fotografía, como si el poema le construyera un nuevo pie de página que reconfigurara por completo el comentario del Jornal do Brasil, de la prensa en general y aun de los objetivos ejemplificadores de un asesinato monstruoso y con vinculaciones con la dictadura. ${ }^{13}$ Reinscribir en el espacio del arte la imagen de un cuerpo muerto fue el primer objetivo del homenaje, y la deixis con la que comienza el poema, el "aqui está e ficará" buscó contraponerse a otro tipo de presencia que la prensa y la dictadura quisieron construirle a Cara de Cavalo. La lógica represiva del gobierno militar había autorizado un castigo ejemplar para quien había osado, aun sin mucha voluntad, enfrentarse a la policía. La reiterada exhibición de ese cuerpo en los medios masivos constituyó una advertencia. El "aquí está e ficará" de Oiticica, en cambio, funda un nuevo modo de la presencia, dotando a ese cuerpo, protegido por un velo y retirado del régimen de obscenidad al que lo había condenado la prensa, de una condición imborrable. $\mathrm{Y}$ a esa presencia muda pero potente contribuye la multiplicación de fotografías en cada cara del Bólide y la cita pictórica y crística que hace resonar en esa pose una historia del sufrimiento y la persecución de los marginados. Cara de Cavalo no es un obrero ni un militante, pero el Bólide lo hace reingresar a ese conjunto multiforme, cambiante y sufriente que llamamos pueblo. En la segunda parte del poema, "contemplai seu silêncio heroico" hay un sutil desplazamiento que es importante reconocer. No se nos pide que contemplemos el cuerpo inerte, sino algo tan inmaterial como su silencio, construido con la insistencia de ese cuerpo que nos enfrenta.

Cuando el Che Guevara fue fotografiado en 1967 por Freddy Alborta, la preparación de la escenografía que realizó el ejército boliviano incluyó que ese cadáver tuviera los ojos abiertos. En relación a esos ojos abiertos, Jorge Castañeda apunta lo siguiente:
11. Enumero unos pocos ejemplos: Lamentación sobre Cristo Muerto (1480-1490), Mantegna; Lamentación sobre Cristo Muerto (1305-1306), Giotto; Llanto por Cristo Muerto (1555-1559), Tintoretto; Llanto y sepultura de Cristo (1438-1443), Fra Angélico; Santo Entierro (15001501), Miguel Ángel; Traslado de Cristo (1507), Rafael Sanzio. Por otra parte, el descenso de Cristo muerto de la cruz es la decimotercera parada del vía crucis, y su muerte se recuerda el día viernes durante la Semana Santa.

12. Dos años después, en octubre de 1967 circulará otra fotografía crística, la de Che Guevara asesinado en la selva boliviana. Sobre esa imagen y sus significaciones ver: MESTMAN, Mariano. "La última imagen sacra de la revolución latinoamericana", 2006.

13. Milton Le Cocq fue um famoso detetive de polícia do estado de Rio de Janeiro, integrante de la custodia personal de Getúlio Vargas, y líder de las Brigadas de la muerte. En 1965, después de su muerte, fue fundada la Scuderie Detective Le Cocq, que llegó a reunir más de siete mil integrantes. 
14. Apud MESTMAN, Mariano. "La última imagen sacra de la revolución latinoamericana”, 2006, p. 4.

15. La hora de la estrella, 2010 , p. 93.

16. En el estudio que Oiticica realizó para el bólide en junio de 1965, en la página 2 dice: "Es decir entramos no sentir de espacio sagrado de tempo lugar de meditación o peregrinación de celebración de la existencia, espacio para pensar la nueva religión". Archivo Hélio Oiticica $n^{\circ} 1753 / 65$.

\section{In Vida precaria. El poder del} duelo y la violencia, 2006, p. 65.

18. El documento no 2149 del Archivo Hélio Oiticica certifica que eran fotografías del documento de identidad. Lo que no dice es cómo las consiguió.

\section{Sostiene BENJAMIN: "El}

valor cultural de la imagen tiene su último refugio en el culto al recuerdo de los seres queridos, lejanos o desaparecidos. En las primeras fotografías vibra por vez postrera el aura en la expresión fugaz de una cara humana. Y esto es lo que constituye su belleza melancólica e incomparable", in "La obra de arte en la época de la reproductibilidad técnica". Conceptos de filosofía de la historia, 2007, p. 157. [...](el Che) se había convertido en el Cristo de Vallegrande, reflejando en sus límpidos ojos abiertos la tranquilidad del sacrificio consentido. El ejército boliviano cometió su único error de campaña una vez consumada la captura de su máximo trofeo de guerra. Transformó al revolucionario resignado y acorralado, al indigente de la Quebrada del Yuro, vencido con todas las de la ley, envuelto en trapos y con la cara ensombrecida por la furia y la derrota, en la imagen crística de la vida que sigue a la muerte. Sus verdugos le dieron rostro, cuerpo y alma al mito que recorrería el mundo $\left[\ldots . .{ }^{14}\right.$

Si los ojos abiertos del Che fundaron una persistencia, la marcación deíctica del poema de Hélio Oititica y su descripción basada en el silencio convierten a este cuerpo muerto, presentado en la prensa como definitivamente acabado, en un cuerpo activo. Entre poema y fotografía se construye la obstinación de permanecer allí. En este sentido, lo que Clarice escribió sobre la muerte de Macabea, otra marginal asesinada, puede describir la presencia de ese cuerpo: "Acostada y muerta, era tan grande como un caballo muerto". ${ }^{15}$ Trasladado a esa pequeña urna, este otro cavalo se vuelve inocultable. ${ }^{16}$

Dos años más tarde, en 1968, Oititica completa su operación con el Bólide Caracara com Cara de Cavalo, que debe leerse en conjunto con el primero. Si el primero, al reenmarcar una foto del periódico, desactiva la infamia de esa muerte obscena y la vuelve activa, este segundo es una invitación al duelo. Judith Butler sostiene que la esfera pública se configura a partir de la prohibición de ciertos duelos: "Lo público se forma sobre la condición de que ciertas imágenes no aparezcan en los medios, de que ciertos nombres no se pronuncien, de que ciertas pérdidas no se consideren pérdidas y de que la violencia sea irreal y difusa". ${ }^{17} \mathrm{Al}$ transformar a Cara de Cavalo en un sujeto que debía ser matado, el poder público le negaba el derecho al duelo y el derecho a ser llorado. Para la dictadura brasileña, no había nada que lamentar en esa muerte. Para construir un dispositivo de duelo, Oiticica construyó su Bólide a partir de dos cajas superpuestas. La inferior traía en su interior ceniza y pedregullo que debía desparramarse en el suelo y construir un territorio que rodeara al Bólide, mientras que la superior terminaba de darle, una vez más, una forma de urna. En el fondo de la caja se observa una foto carnet ampliada del documento de Cara de Cavalo, resignificando en este caso el poder clasificatorio de una foto carnet y convirtiéndola en una presencia muda de un rostro al que somos invitados a observar. ${ }^{18}$ El Caracara funciona como una ceremonia de duelo a través de esa mirada singular, pues el rostro, como ha advertido Walter Benjamin, es el último refugio de la pérdida del aura. ${ }^{19}$ Se recupera aquí el "esto ha sido" barthesiano, y se profundiza en el carácter funerario de la 
imagen de Cara de Cavalo. Al mostrárnoslo situado y vivo frente a una cámara que alguna vez lo captó para darle una identidad, el Bólide también nos habla de su futura ausencia por asesinato. ${ }^{20}$

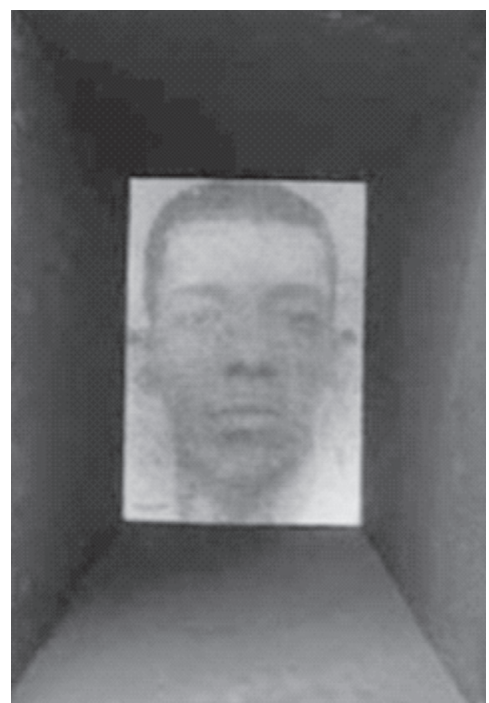

Fig. 4. Bólide caixa 24 "Caracara Cara de Cavalo"

\section{Héroes}

"We can be Heroes, just for one day"

David Bowie

Oiticica utilizó la categoría de "héroe" o "antihéroe" para referirse a sus Bólides de homenaje a bandidos. Además de los dedicados a Cara de Cavalo produjo el B44 Bólide-caixa 21 caixapoema 3: porque a impossibilidade?, para el que utilizó la fotografía de otro bandido muerto en 1966, que se suicida a orillas del río Timbó al verse rodeado por la policía luego de robar un banco. La historia de Alcir Figueira apenas fue cubierta por la prensa y su muerte cayó pronto en el olvido. La postura del cadáver de Alcir Figueira es muy semejante a la de Cara de Cavalo, y la operación de Oiticica reproduce el diseño de su primer Bólide. Se apropia y reenmarca una fotografía de la prensa con una pose crística y vuelve a disputar los sentidos fabricados por los medios masivos en torno a la vida de los hombres infames. ${ }^{21}$

A partir de ese Bólide, Oiticica construyó una bandera a la que le estampó el eslogan "Seja marginal, seja herói". Esa bandera fue exhibida por primera vez en el Festival das Bandeiras realizado en la Plaza General Osório, en febrero de 1968. Respecto de ese festival Frederico Morais escribía un comentario esclarecedor en el Diario Noticias,
20. Eduardo Cadava ha señalado, poniendo en relación fotografía y muerte: "La persistencia del fotografiado nunca es únicamente la persistencia de su vida sino también de su muerte. [...] Al fotografiar a alguien, sabemos que la imagen lo sobrevivirá: ella comienza a circular sin el retratado -incluso durante su vida-, figurando y anticipando su muerte cada vez que la contemplamos. La fotografía es una despedida. Pertenece al después de lo fotografiado. Está permanentemente iluminada por el destello momentáneo de su muerte". CADAVA, Eduardo. Trazos de luz. Tesis sobre la fotografía de la historia, 2006, p.63-64.

21. El Bólide dedicado a Alcir Figueira también está acompañado de un poema. Lamentablemente debido a que no existen registros fotográficos que den cuenta de la totalidad del poema, de que en los archivos de Oiticica no haya registro de tal poema, y de que el Bólide pertenezca a un coleccionista privado, sólo tenemos la imagen de un fragmento en el que, además del título, se pueden leer o intuir las siguientes palabras: "a existencia", "buscou" (suponemos), "crime", "querer". Estas cuatro palabras, sin embargo, no permiten construirle un sentido. 


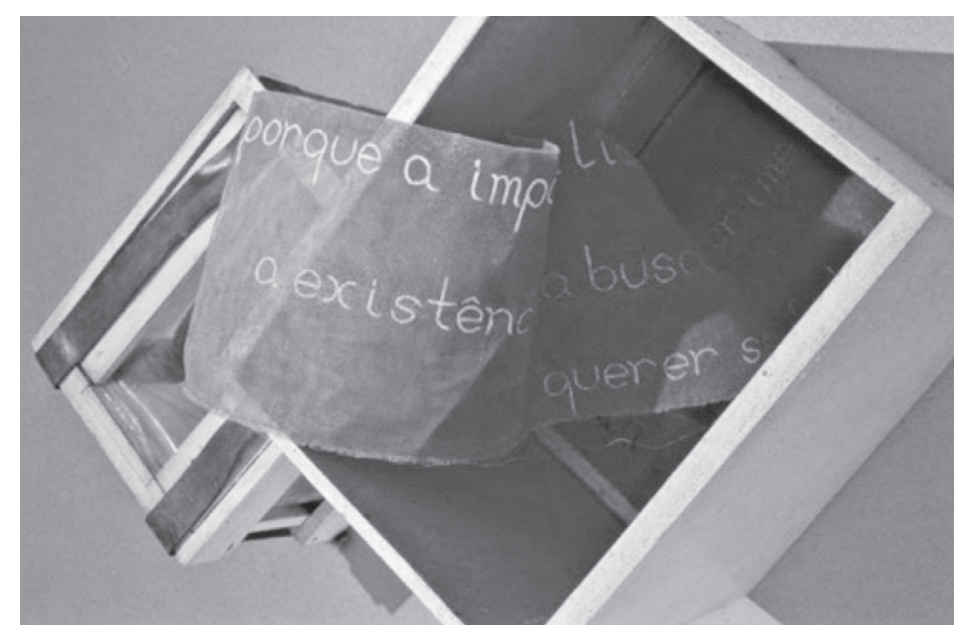

Fig. 5. Detalle del B44 Bólide-caixa 21 caixa-poema 3: porque a impossibilidade?

22. Archivo Hélio Oiticica, documento $\mathrm{n}^{\circ} 1877 / 68$.

23. Sabemos además que esa bandera fue exhibida el 14 de octubre de 1968 en la confitería Sucata durante un show de Caetano Veloso y Gilberto Gil, y que en esa ocasión un promotor de justicia y un delegado del DOPS exigen del propietario de local la retirada del estandarte. Sucata es clausurada al día siguiente y poco menos de dos meses después Caetano Veloso y Gilberto Gil son encarcelados por la dictadura, mientras Oiticica parte para Londres con Torquato Neto.

24. El eslogan también posee una estructura de anuncio publicitario: a partir de la asunción de una conducta nos promete algún tipo de recompensa.

\begin{abstract}
A bandeira é participante, quem a faz o usa compremetese com uma idéia, com um movimento, grupo, partido, organização (política ou esportiva, religiosa ou profissional): Vietcongs, Resistencia, Nacional-Socialismo, Flamengo, MDB (será que tem ou leva alguma bandeira?), etc. É um símbolo e não mero suporte, uma tela maior. A bandeira está comprometida com a rua, com a massa, com o povo, e deve, portanto, falar a sua linguagem, usar seu vocabulário. ${ }^{22}$
\end{abstract}

Es importante recordar que en junio del 68 se produjo la passeata dos cem mil, una manifestación multitudinaria en contra de la dictadura, en donde la pancarta y el eslogan funcionaron como instrumentos centrales de la protesta. A ese tipo de circulación apuntaba Oiticica, pública, popular y enmarcada por una protesta. ${ }^{23}$ El eslogan, "Seja marginal, seja herói”, refuerza la intención pública del objeto. El enunciado abandona el pedido de contemplación y exige al espectador una acción determinada: volverse marginal y de este modo convertirse en héroe. ${ }^{24}$ Cambia la finalidad del arte de Oiticica y el lugar que pretendía como artista, o mejor habría que precisar, cesa la excepcionalidad contemplativa de los tres Bólides mencionados. Nuevamente, como con los Parangolés, como con las instalaciones, su arte se propone expandirse sobre lo social, volverse social. El modelo de artista que Oiticica asume aquí es el de incitador de conductas.

Oiticica trabajó las potencias de lo plebeyo sin borrar la historicidad, el contexto y la identificación, es decir sin borrar el studium con que necesariamente deben ser leídas esas fotografías. Construyó un marco como un acto de justicia para con las figuras de los vencidos, y de este modo las reinscribió en el dominio del arte para desde allí volver a reinscribirlas en la esfera pública. Sin embargo, como apuntábamos, todo marco es insuficiente porque siempre surge una dimensión de lo intratable en tanto resistencia. Eso intratable, la persistencia del cuerpo anunciada por el poema o la mirada de la foto carnet ampliada, puede ser 
pensado como otra forma de la justicia. Al producir presencias brutas se enhebra una dimensión inescindible de pasividad y actividad, escapando a la martirización y la heroización. ${ }^{25}$ El trabajo de Oiticica en sus Bólides, y el de toda una zona del arte que se confrontó con figuras del pueblo, consistió en construir una inscripción que no fuera ni un puro studium que subsumiera toda singularidad, y las potencias que de ella pudieran emanar, ni un puro punctum, que hiciera peligrar la memoria de los vencidos en función de una vida puramente anónima y tal vez por ello ineficaz en su apelación. El estandarte-bandera, en cambio, dramatizó la pulsión de un arte que no se contentaba con una resistencia muda y contemplativa, sino que se imaginaba en las calles, en medio de la vida cotidiana, sumándose al continuo de la existencia hasta tornarse indiscernible con la vida que lo rodeaba. Entre los Bólides y el estandarte-bandera, en esa breve pero intensa trayectoria, se pueden percibir los tanteos, las marchas y contramarchas de las relaciones que el arte procuró establecer con la política de su tiempo durante los años sesenta.

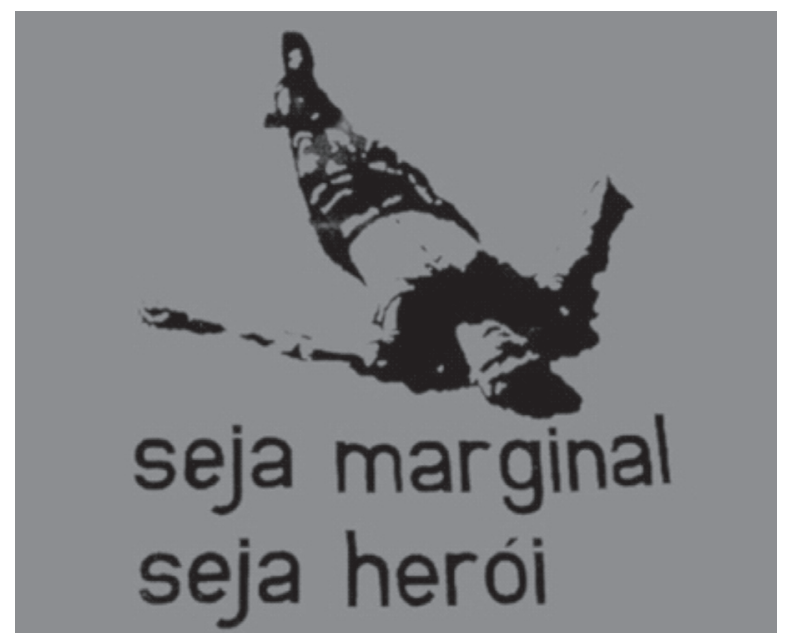

Fig. 6. Estandarte-bandera Seja marginal, seja herói

\section{Referencias}

AGUILAR, Gonzalo. "La ley del bandido, la ley del arte. Bólide caixa 18 poema Caixa 2, Homenagem a Cara de Cavalo de Hélio Oiticica”. Revista Iberoamericana, Vol XXV, No 227, Abril-junio 2009.

BENJAMIN, Walter. Conceptos de filosofía de la historia. Buenos Aires: Caronte, 2007.

BUTLER, Judith. Vida precaria. El poder del duelo y la violencia. Buenos Aires: Paidós, 2006.
25. In Pueblos expuestos, pueblos figurantes, 2014, p.80. 
CADAVA, Eduardo. Trazos de luz. Tesis sobre la fotografía de la historia. Santiago de Chile: Palinodia, 2006.

COELHO, Fred. Livro ou Livro-me. Os escritos babilónicos de Hélio Oiticica (1971-1978), Río de Janeiro: EDUERJ, 2008.

DIDI-HUBERMAN. Georges. Pueblos expuestos, pueblos figurantes. Buenos Aires: Manantial, 2014.

GARRAMUÑO, Florencia. La experiencia opaca. Literatura y desencanto. Buenos Aires: Fondo de Cultura, 2009.

LISPECTOR, Clarice. La hora de la estrella. Buenos Aires: Corregidor, 2010.

MESTMAN, Mariano. "La última imagen sacra de la revolución latinoamericana". Revista Ojos Crueles. Temas de fotografía y sociedad, n. 3, Buenos Aires, n. 3, octubre 2006.

OITICICA, Hélio. Materialismos. Buenos Aires: Manantial, 2013

VARELA LOEB, Ângela. "Os bólides do Programa Ambiental de Hélio Oititica”. Ars n 17, San Pablo, 2011. 